\title{
Biometria de frutos e sementes e tratamentos pré-germinativos em Cassia fistula L. (Fabaceae-Caesalpinioideae)
}

\section{Fruits and seeds biometry and pre-germination treatments in Cassia fistula L. (Fabaceae-Caesalpinioideae)}

\author{
Francisco Thiago Coelho Bezerra ${ }^{1 *}$; Leonaldo Alves de Andrade ${ }^{2}$; \\ Marlene Alexandrina Ferreira Bezerra ${ }^{3}$; Maria Lúcia Maurício da Silva ${ }^{1}$; \\ Raphaella Cristina Resende Nunes ${ }^{4}$; Edilson Guedes da Costa ${ }^{5}$
}

\section{Resumo}

Este trabalho objetivou caracterizar a morfometria de frutos e sementes de Cassia fistula L. (Fabaceae) e estudar técnicas, mecânica e física, como tratamentos pré-germinativos das sementes desta espécie. As medidas de comprimento, diâmetro, espessura, massa fresca e número de sementes por fruto foram tomadas em uma amostra de 100 frutos, retirada aleatoriamente do lote coletado no município de SouzaPB. Após a extração das sementes dos frutos retirou-se, aleatoriamente, amostra de 100 propágulos para as determinações de comprimento, diâmetro, largura, massa fresca, massa de 1.000 sementes e umidade. Para a superação da dormência foram empregadas as seguintes técnicas: sem escarificação e escarificadas nas faces lateral e oposta ao hilo, sendo estes tratamentos mecânicos sem e com embebição em água destilada por 12 e 24 horas, utilizando-se 100 sementes por tratamento, divididas em quatro repetições. Após aplicação dos tratamentos, as sementes foram semeadas em areia autoclavada. A eficiência dos tratamentos foi avaliada pelas varáveis: primeira contagem da emergência, emergência, índice de velocidade da emergência, tempo médio da emergência e comprimento e biomassa seca da parte aérea e radicular das plântulas. Frutos e sementes de C. fistula possuem, em média, 414 e 8,28 mm de comprimento; 18,9 e 6,25 mm de diâmetro; 20,9 e 3,54 mm de espessura e; 67,3 e 0,1474 g de massa fresca, respectivamente. As escarificações são eficiente para superar a dormência de sementes de C. fistula, aumentando acima de 90 e 50\% para as variáveis de emergência e crescimento das plântulas, respectivamente. A embebição em água por até 24 horas não promove superação de dormência. A escarificação aumenta a emergência e o vigor das plântulas de $C$. fistula.

Palavras-chave: Espécie florestal, morfometria, dormência, embebição, escarificação

\footnotetext{
Abstract

This study aimed to characterize the morphology of fruits and seeds of Cassia fistula L. (Fabaceae) and study techniques, mechanics and physics as pre-germination of seeds of these species treatments. Measurements of length, diameter, thickness, fresh weight and number of seeds per fruit were taken at a sample of 100 fruits, selected at random from the lot of the municipality of Souza-PB. After extraction

${ }^{1}$ Eng $^{\text {os }}$ Agr ${ }^{\text {os }}$, Discentes do Programa de Pós-Graduação em Agronomia, UFPB, CCA, Areia, PB. E-mail: bezerra_ftc@yahoo.com. br; luciagronomia@hotmail.com

${ }^{2}$ Eng $^{\circ}$ Agr $^{\circ}$, Prof. Dr., UFPB, CCA, Areia, PB. E-mail: landrade@cca.ufpb.br

${ }^{3}$ Eng $^{\mathrm{a}} \mathrm{Agr}^{\mathrm{a}}$, Mestre em Ciência do Solo, UFPB, CCA, Areia, PB. E-mail: marlene_agro@hotmail.com

${ }^{4}$ Discente do Curso de Graduação em Agronomia, UFPB, CCA, Areia, PB. E-mail: raphaellaresende@hotmail.com

${ }^{5}$ Eng $^{\circ}$ Agr ${ }^{\circ}$, UFPB, CCA, Areia, PB. E-mail: didiuguedes2000@hotmail.com

* Autor para correspondência
} 
of seeds from fruits withdrew randomly sample of 100 seedlings for the determination of length, diameter, width, fresh weight, mass of 1,000 seeds and humidity. To overcome dormancy were used the following techniques: without scarification and scarified cheeks and side opposite to the hilum, and these mechanical treatments with and without soaking in distilled water for 12 to 24 hours, using 100 seeds per treatment divided in four replications. After application of the treatments, the seeds has been were sown in trays containing autoclaved sand. The effectiveness treatments measured by variables: first count, emergency, rate of emergence, mean time of emergence and length and dry weight of shoots and roots of seedlings. Fruits and seeds of $C$. fistula have, on average, 414 and $8.28 \mathrm{~mm}$ in length; 18.9 and $6.25 \mathrm{~mm}$ in diameter; 20.9 and $3.54 \mathrm{~mm}$ in thickness and; 67.3 and $0.1474 \mathrm{~g}$ of fresh, respectively. The scarification is efficient to overcome the dormancy of C. fistula, rising above 90 and $50 \%$ variables emergence and seedling growth, respectively. The soaking in water for 24 hours does not promote breaking dormancy. Scarification improves emergence and seedling vigor of C. fistula.

Key words: Forest species, morphology, dormancy, imbibition, scarification

\section{Introdução}

A espécie Cassia fistula L., comumente conhecida por chuva-de-ouro, cana imperial ou ainda canafístula verdadeira, é uma leguminosa Caesalpinoideae do gênero Cassia. Nativa das regiões tropicais da Ásia, apresenta-se naturalmente distribuída em toda a Índia, Indochina e Malásia (ROCAS, 2002; ORWA et al., 2009). Segundo Rocas (2002), a espécie foi introduzida nas regiões tropicais da África e América. No Brasil a espécie, encontra-se disseminada por quase todo o País, com melhor desempenho na faixa litorânea de clima tropical, onde é cultivada com fins ornamentais e na arborização de ruas, praças e jardins (CORRÊA, 1984).

Além das características supracitadas, a C. fistula possui outros atributos que a põem em destaque: a polpa do fruto é usada como laxante, sua madeira é dura, pesada e considerada durável, adequada para marcenaria, implementos agrícolas e construção e, também é utilizada como lenha (ROCAS, 2002; ORWA et al., 2009). De acordo com Orwa et al. (2009), a espécie é ainda utilizada para alimentação, pois suas flores são consumidas por pessoas na Índia, além de servir para a apicultura. Sua casca, rica em tanino, tem sido empregada na indústria de curtimento de peles.

O comportamento vegetativo e reprodutivo, bem como os padrões biométricos de espécies vegetais podem ser influenciados pelo meio biofísico ao qual estejam submetidas. Assim, a caracterização biométrica criteriosa de frutos e sementes constitui uma ferramenta importante, inclusive para identificar espécies fenotipicamente semelhantes. Tais caracterizações morfométricas além de possibilitar a diferenciação de espécies congêneres (ALVES et al., 2007), auxilia no reconhecimento da forma de dispersão do táxon e a maneira em que se estabelecem suas plântulas (FENNER, 1993).

As diferenças biométricas estão relacionadas não só a fatores ambientais, mas também às reações da população ao estabelecimento em um novo ambiente, principalmente quando a espécie tem uma ampla distribuição (RODRIGUES et al., 2006). Já as variações de tamanho de sementes existentes na própria planta são decorrentes dos efeitos do ambiente durante o seu desenvolvimento (LEISHAMAN et al., 2000) e, essas variações podem interferir na qualidade fisiológica das sementes (OLIVEIRA et al., 2009). De acordo com Noodén, Blakey e Grzybowski (1985), a maior espessura do tegumento induzida pela seca é considerada uma resposta adaptativa a condições de déficit hídrico ou de semiaridez.

Segundo Brancalion e Marcos Filho (2008), há fortes evidências de que a dormência é uma resposta adaptativa às condições ambientais locais. Mas, pode estar diretamente relacionada à planta matriz como também a localização da sementes. Estes autores relatam que a própria planta-mãe detecta os fatores 
que favorecem à dormência ou, antagonicamente, favorece o aumento da germinação, tais como regime de temperatura na fase pré-antese, fotoperíodo, deficiência hídrica, estado nutricional da planta. Uma das dormências encontradas em espécies florestais é a do tipo tegumentar, comum na maioria das espécies da família Fabaceae.

A dormência torna-se um dos principais obstáculos no processo de propagação das espécies florestais pois, dificulta a produção uniforme de mudas tanto na regeneração natural, quanto em viveiro (SANTOS et al., 2003) mas, o procedimento que resulte na ruptura ou enfraquecimento do tegumento deve ser aplicado às sementes, pois facilitará a entrada de água e gases e, com isso, permitindo o início do processo germinativo e a emergência de plântulas (FOWLER; BIANCHETTI, 2000).

A escarificação mecânica é um dos tratamentos mais utilizados para espécies que apresentam sementes com impermeabilidade tegumentar, pois promove uma maior embebição de água pelas sementes, por aumentar a sua permeabilidade por fissuras, acelerando assim o início do processo germinativo. A escarificação é uma técnica eficiente e comprovada para várias espécies, tais como: Caesalpinia pyramidalis Tul (ALVES et al., 2007); Senna siamea (Lam.) H.S. Irwin E Barneby (DUTRA et al., 2007); Mucuna aterrima (Piper et Tracy) e Mucuna aterrima (Piper et Trace) Holland (NAKAGAWA et al., 2007); Acacia magium Willd (RODRIGUES et al., 2008); Zizyphus joazeiro Mart. (ALVES et al., 2008); Adenanthera pavonina L. (RIBEIRO; BRAZ; BRITO, 2009).

Outra técnica utilizada para superação de dormência tegumentar consiste na imersão das sementes em água, sendo o tempo de embebição um fator chave para muitas espécies, visto que algumas absorvem rapidamente a água e outras demandam um período mais longo (GALINDO, 2006), havendo também diferenças no tempo de embebição nos diferentes tecidos das sementes (MARCOS FILHO,
2005). A embebição das sementes também está relacionada com a eliminação de problemas, que normalmente é decorrente de longos períodos de armazenamento e que causa a secagem excessiva das sementes, impedindo-as de absorver água e iniciar o processo germinativo (FOWLER; BIANCHETTI, 2000)

Diante do exposto, o presente trabalho objetivou caracterizar a morfometria de frutos e sementes de Cassia fistula L. (Fabaceae) e estudar técnicas, mecânica e física, como tratamentos prégerminativos das sementes desta espécie.

\section{Material e Métodos}

Os frutos de Cassia fistula L. (Fabaceae) foram coletados no estádio maduro de diferentes árvores, caracterizado pelo desprendimento dos mesmo das plantas-mãe, sendo o lote formado por dois sacos de $60 \mathrm{Kg}$. O material em estudo, frutos e sementes, foi coletado no perímetro irrigado do município de Souza-PB, situado entre os paralelos $6^{\circ} 19^{\prime}$ e $7^{\circ} 24^{\prime}$ $\mathrm{S}$ e os meridianos $37^{\circ} 55^{\prime}$ e $38^{\circ} 46^{\prime} \mathrm{W}$, com altitude média de 235 m (SILVA NETO et al., 2012). O clima da região, de acordo com a classificação de Köppen, é do tipo Aw', ou seja, clima tropical com estação seca. A precipitação pluvial média anual é de $800 \mathrm{~mm}$ concentrada entre janeiro a abril, com temperaturas variando entre 25 a $38^{\circ} \mathrm{C}$ e umidade relativa do ar média de $64 \%$. O tipo de solo predominante na região são os Neossolos Flúvicos em um relevo plano e suavemente ondulado.

As determinações da morfometria carpo-seminal e os tratamentos pré-germinativos das sementes foram realizadas na estufa telada do Laboratório de Ecologia Vegetal (LEV), do Departamento de Fitotecnia e Ciências Ambientais (DFCA), do Centro de Ciências Agrárias (CCA), da Universidade Federal da Paraíba (UFPB), Areia-PB.

Biometria de frutos e sementes 
As determinações morfométricas dos frutos foram tomadas a partir de 100 unidades, retiradas aleatoriamente do lote coletado, medindo-se o comprimento com auxílio de fita métrica, largura (medida próximo às extremidades e na região mediana) e espessura (medida próximo às extremidades e na região mediana) com paquímetro digital e massa fresca em balança eletrônica (precisão de 0,02 g). Em seguida, os frutos foram quebrados com martelo para a obtenção das sementes, as quais foram submetidas à lavagem em água corrente para retirada da mucilagem. A partir de então, determinou-se o número de sementes normais e danificadas por fruto, considerando como danificadas aquelas sementes atacadas por pragas e/ ou mau formadas.

Das sementes normais obtidas, foram retiradas 100 unidades de forma aleatória para determinações de comprimento, diâmetro e espessura com auxílio de paquímetro digital e, massa fresca em balança eletrônica (precisão 0,0001 g). Também se determinou a massa de 1.000 sementes a partir de oito amostras de 100 sementes (BRASIL, 2009) e o teor de água, pelo método da estufa a $105 \pm 3{ }^{\circ} \mathrm{C}$ por 24 horas, a partir de quatro amostras de 25 sementes.

\section{Tratamentos pré-germinativos}

Para superar a dormência da espécie, as sementes de C. fistula foram submetidas aos seguintes tratamentos: sem escarificação, escarificação com lixa $n^{\circ} 80$ na região lateral ao hilo e na região oposta ao hilo (FOWLER; BIANCHETTI, 2000), sendo estes tratamentos mecânicos sem e com embebição em água destilada por 12 e 24 horas à temperatura ambiente, totalizando nove tratamentos. Para cada tratamento foram utilizadas 100 sementes divididas em quatro repetições.

Depois de submetidas aos tratamentos, as sementes foram colocadas paragerminarem bandejas plásticas com dimensões de 48,5 cm de comprimento x $33 \mathrm{~cm}$ de largura x $6,6 \mathrm{~cm}$ de profundidade, as quais foram divididas em quatro subunidades $\mathrm{e}$ preenchidas com areia lavada e autoclavada. As bandejas foram dispostas nas bancadas da estufa telada do LEV/CCA/UFPB de forma casualizada e irrigadas diariamente. As avaliações da emergência foram realizadas diariamente, até o vigésimo sétimo dia, sendo consideradas emergidas as plântulas que apresentavam os cotilédones totalmente liberados do substrato.

As variáveis analisadas foram: índice de velocidade de emergência (IVE) - calculado conforme a fórmula proposta por Maguire (1962); primeira contagem - considerando a porcentagem de plântulas normais emergidas no sétimo dia após o semeio; tempo médio de emergência (t) correspondendo ao tempo gasto para a emergência total; percentual de emergência - número de plântulas normais emergidas ao final do período de avaliação, considerado como final da avaliação quando a leitura de emergência estabilizou-se $\left(27^{\circ}\right.$ dias após a semeadura); comprimento da parte área (CPA) e da raiz (CR) - ao final do período de contagens as plântulas normais foram separadas em parte área e raiz por corte na inserção do colo, sendo medido seu comprimento com auxilio de régua graduada em milímetros; massa seca da parte área (MSPA) e da raiz (MSR) - após a medição do comprimento da parte aérea e radicular das plântulas, as mesmas foram colocadas para secar até atingir massa constante em estufa de circulação forçada de ar a $65^{\circ} \mathrm{C}$ e, em seguida, pesadas em balança analítica.

O delineamento experimental utilizado foi o inteiramente ao acaso, em esquema fatorial de $3 \times 3$ sendo, três tratamento mecânicos combinados com três períodos de embebição. Para análise estatística, os dados em porcentagem foram transformados para a função Arco-seno $(\mathrm{X} / 100)^{1 / 2}$, afim de, homogeneizar as variâncias.

\section{Análises estatísticas}

Os dados biométricos dos frutos e das sementes foram analisados em classes de frequência, cujo 
número de classes foi obtido pela fórmula de Sturges e o intervalo das classes pelo do método das variáveis contínuas. Para esta análise utilizouse o software BioEstat ${ }^{\circledR}$ versão 5.0 (AYRES et al., 2007).

Os tratamentos pré-germinativos foram verificados pela análise de variância (ANOVA) para avaliar os efeitos significativos dos fatores e sua interação e, para identificar as diferenças entre médias dos tratamentos utilizou-se o teste de Tukey ( $\mathrm{p} \leq 0,05)$. Para estas análises utilizou-se o software SISVAR ${ }^{\circledR}$ versão 5.3 (FERREIRA, 2010).

\section{Resultados e Discussão}

Na Figura 1 (A, B, C e D), pode ser observada a distribuição de frequência dos dados biométricos dos frutos de C. fistula, referentes ao comprimento, diâmetro, espessura e massa fresca, com suas respectivas médias e desvios padrão. Os frutos de $C$. fistula apresentaram as seguintes médias com seus desvios padrão $41,4 \pm 10,2 \mathrm{~cm}, 18,9 \pm 2,1 \mathrm{~mm}, 20,9 \pm 2$ mm e $67,3 \pm 23,5$ g de comprimento, diâmetro, espessura e massa fresca, respectivamente. A classe de frequência mais representativa foi de $50,5 \mathrm{~cm}$ (32\%) para o comprimento, de $18,8 \mathrm{~mm}(34 \%)$ para o diâmetro, de $20,7 \mathrm{~mm}$ (37\%) para a espessura e de 81,9 g para a massa fresca do fruto $(28 \%)$.

Figura 1. Frequência, média e desvio padrão do comprimento (A), do diâmetro (B), da espessura (C) e da massa da matéria fresca (D) dos frutos de Cassia fistula L., Areia-PB, 2009.
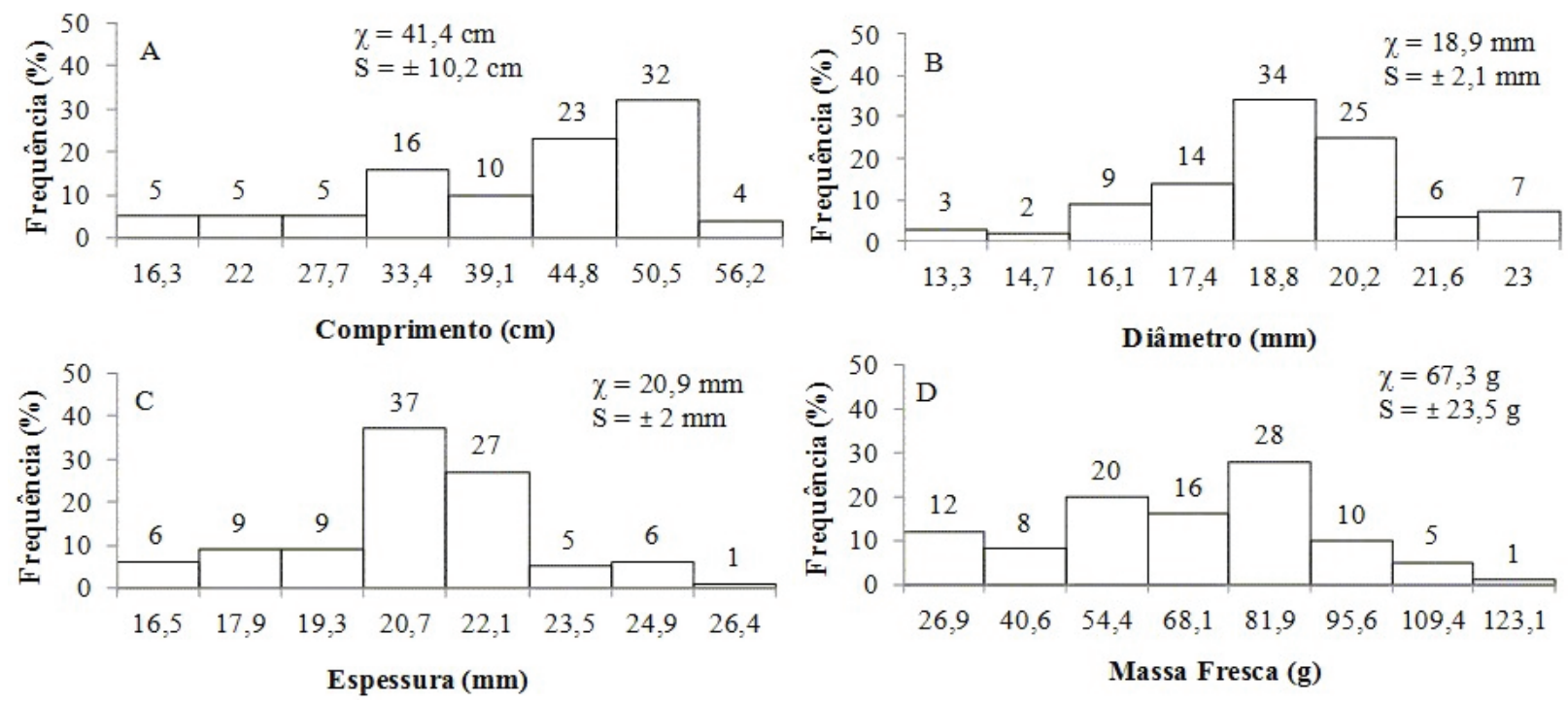

$\chi$ e S: média e desvio padrão, respectivamente.

Fonte: Elaboração dos autores.

Na descrição morfológica de frutos de Cassia fistula, Rocas (2002) os descreveu como legumes, de formato linear-cilíndrico, de 30 a $50 \mathrm{~cm}$ de comprimento e 1,5 a $1,7 \mathrm{~cm}$ de diâmetro, com coloração castanho-escuro ao preto e indeiscente quando maduros. Enquanto para Orwa et al. (2009), os frutos de C. fistula possuem comprimento de 40 a $60 \mathrm{~cm}$ e diâmetro de $1 \mathrm{a} 2 \mathrm{~cm}$, formato cilíndrico e caráter indeiscente.

As variações encontradas nas dimensões dos frutos de $C$. fistula, neste trabalho e nos trabalhos aqui citados, podem estar relacionadas com os fatores genéticos e ou com interações genótipo ambiente, pois, como já foi ressaltado (RODRIGUES et 
al., 2006), os táxones e os fatores ambientais podem interagir, resultando no estabelecimento de distintos padrões morfométricos entre populações espacialmente distribuídas.

$\mathrm{O}$ número de sementes (Figura 2) foi, em média, de $53 \pm 18$ sementes normais e $3 \pm 4$ sementes danificadas por fruto. Na relação entre as sementes normais e danificadas, observa-se o predomínio das sementes normais $(94,32 \%)$ em comparação com as sementes danificadas $(5,68 \%)$ sendo, as respectivas classes de frequência as mais representativas, $63(44,96 \%)$ e $7(4,86 \%)$ sementes por fruto. Em relação à variação do número de sementes por fruto, Orwa et al. (2009) encontraram desde 25 a 100 sementes por fruto.

Figura 2. Frequência, média e desvio padrão do número de sementes normais ( $\square$ ) e danificadas ( $\square$ ) em fruto de Cassia fistula L., Areia-PB, 2009.

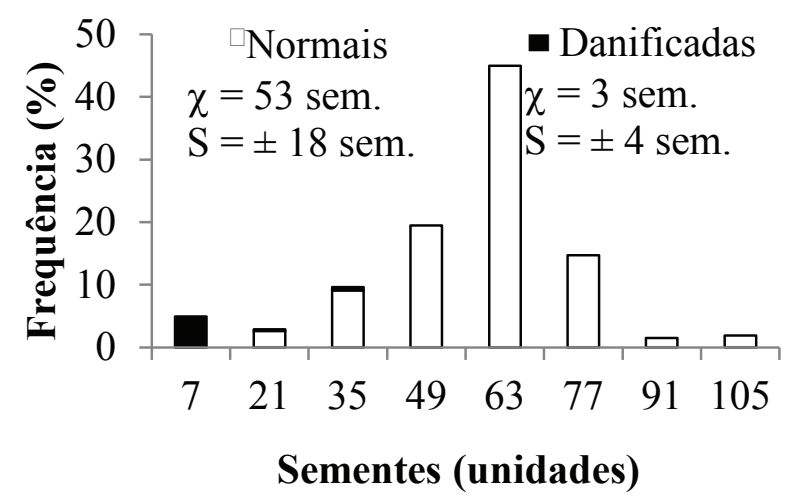

Observa-se que ocorreu predomínio de sementes normais em relação às sementes danificadas nos frutos de C. fistula (Figura 2). Neste sentido, Lopes et al. (2003) observaram, para esta mesma espécie, $56 \%$ de sementes viáveis e sadias, $23 \%$ de carunchamento e $21 \%$ com mal formações. A garantia da perpetuação, diversificação e propagação de muitas espécies está associada a produção de sementes. Dessa forma, espécies que produzem muitos frutos, contendo elevado número de sementes viáveis possuem maiores alcances geográficos. No caso de C. fistula foi observado predomínio das sementes normais; o que possivelmente venha contribuir com o sucesso de sua dispersão (CORRÊA, 1984; ROCAS, 2002; ORWA et al., 2009).

A distribuição de frequência, a média e o desvio padrão do comprimento, do diâmetro, da espessura e da massa fresca das sementes de $C$. fistula estão apresentados na Figura 3 (A, B, C e $\mathrm{D}$, respectivamente). Os dados biométricos médios e o desvio padrão das sementes de $C$. fistula foram, $8,28 \pm 0,46 \mathrm{~mm}$ de comprimento, $6,45 \pm 0,31$ $\mathrm{mm}$ de diâmetro, 3,54 $\pm 0,47 \mathrm{~mm}$ de espessura e $147,4 \pm 23,8 \mathrm{mg}$ de massa fresca, sendo as classes de frequências mais representativas, 8,22 mm (32\%) de comprimento, $6,52 \mathrm{~mm}$ (24\%) de diâmetro, 3,52 $\mathrm{mm}(27 \%)$ espessura e, 138,4 e $155,3 \mathrm{mg}$ (28\%) de massa fresca.

$\chi$ e S: média e desvio padrão, respectivamente.

Fonte: Elaboração dos autores. 
Figura 3. Frequência, média e desvio padrão do comprimento (A), do diâmetro (B), da espessura (C) e da massa da matéria fresca (D) das sementes de Cassia fistula L., Areia-PB, 2009.
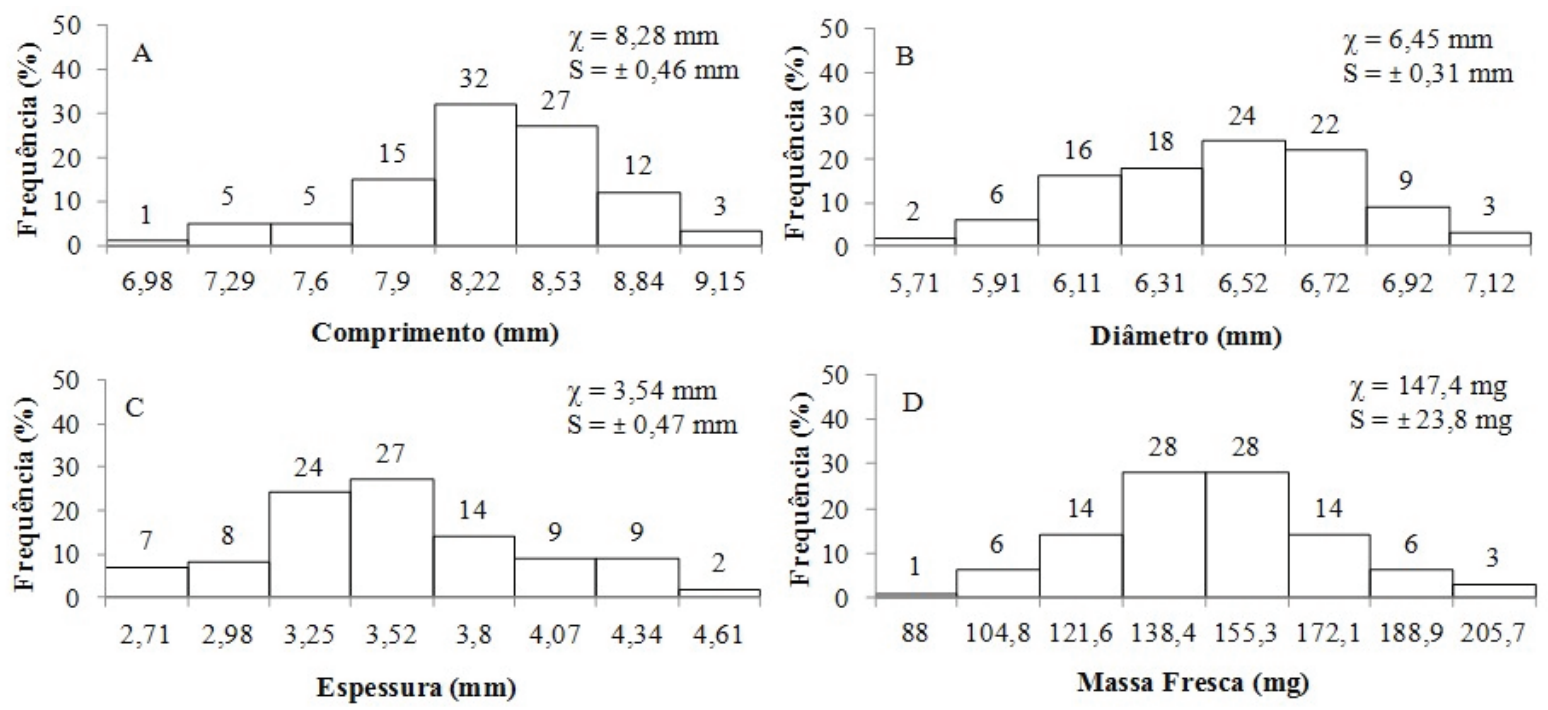

$\chi$ e S: média e desvio padrão, respectivamente.

Fonte: Elaboração dos autores.

De acordo com Rocas (2002), as sementes de $C$. fistula possuem de 7,5 a $10 \mathrm{~mm}$ de comprimento, 6 a 7,5 mm de largura e 2,5 a $3 \mathrm{~mm}$ de espessura e, com formato ovóide a elipsóide, biconvexa com secção transversal e ventralmente achatada. Como também foi evidenciado neste trabalho, as sementes de $C$. fistula possuem pequenas variações nas dimensões e na massa. Lopes et al. (2003), encontraram valores médios de $10 \mathrm{~mm}$ de comprimento e de 7 mm de largura nas sementes de Cassia fistula, sendo superiores aos valores médios aqui demonstrados, mas aproximados. Essas variações supracitadas, podem esta relacionadas à variações genéticas e/ou ambientais.

De acordo com Leishaman et al. (2000), as variações de tamanho de sementes existentes na própria planta, não são provocadas por diferenças genéticas, mas são decorrentes dos efeitos do ambiente durante o seu desenvolvimento. Essas variações podem interferir na sua qualidade fisiológica, a qual ainda é muito pouco pesquisada em espécies florestais (OLIVEIRA et al., 2009).

A amostra de sementes estudada neste trabalho possuía massa de 1.000 sementes de 144,63 g com teor de água de 7,6\%. Lopes et al. (2003), encontraram massa de 1.000 sementes de Cassia fistula com 178,25g, com teor de água de 10,5\%. De acordo com Vaughton e Ramsey (1998), variações na massa de sementes ocorrem em muitas espécies de plantas e, com freqüência, na própria planta.

A escarificação mecânica afetou significativamente (Tabela 1) as variáveis estudadas, exceto a massa seca da raiz (MSR). Já o fator embebição alterou apenas a primeira contagem (PC) e a massa seca da parte aérea (MSPA). Em relação à interação entre os efeitos da escarificação e da embebição, foram observadas afinidades desses fatores apenas com a variável primeira contagem (PC). 
Tabela 1. Resumo da análise de variância para a primeira contagem (PC), a emergência (EMERG), o índice de velocidade de emergência (IVE), o tempo médio de emergência ( $\mathrm{t}$ ), o comprimento da parte aérea (CPA) e da raiz (CR) e massa seca da parte aérea (MSPA) e da raiz (MSR) dos tratamentos pré-germinativos em sementes de Cassia fistula L., Areia-PB, 2009.

\begin{tabular}{|c|c|c|c|c|c|c|c|c|}
\hline \multirow{2}{*}{$\begin{array}{l}\text { Fontes de } \\
\text { Variações }\end{array}$} & \multicolumn{8}{|c|}{ Quadrado Médio } \\
\hline & PC & EMERG & IVE & $\mathbf{t}$ & CPA & CR & MSPA & MSR \\
\hline Escarificação (E) & $1,70 * *$ & $5,78 * *$ & $33,67 * *$ & $1.218,99 * *$ & $71,48 * *$ & $95,24 * *$ & $0,0106^{*}$ & $0,0004^{\text {ns }}$ \\
\hline Embebição (Em) & $0,35 * *$ & $0,04^{\mathrm{ns}}$ & $0,13^{\text {ns }}$ & $25,30^{\text {ns }}$ & $12,27^{\text {ns }}$ & $20,43^{\text {ns }}$ & $0,0079 *$ & $0,0001^{\text {ns }}$ \\
\hline Ex Em & $0,16^{* *}$ & $0,01^{\mathrm{ns}}$ & $0,08^{\mathrm{ns}}$ & $18,83^{\mathrm{ns}}$ & $3,9^{\text {ns }}$ & $1,12^{\mathrm{ns}}$ & $0,0027^{\mathrm{ns}}$ & $0,0001^{\text {ns }}$ \\
\hline Resíduo & 0,02 & 0,02 & 0,05 & 60,41 & 4,14 & 7,84 & 0,002 & 0,0005 \\
\hline CV (\%) & 32,97 & 14,62 & 11,47 & 57,54 & 34,27 & 41,02 & 49,71 & 78,81 \\
\hline
\end{tabular}

ns, * $\mathrm{e}^{* *}=$ não significativo e significativo a 1 e a $5 \%$ de probabilidade pelo teste $\mathrm{F}$, respectivamente.

Fonte: Elaboração dos autores.

$\mathrm{Na}$ primeira contagem de emergência de plântulas de C. fistula, a ausência de embebição não resultou em diferenças significativas entre as sementes escarificadas na lateral e na região oposta ao hilo e entre esta e as sementes intactas (Tabela 2). Já, para os períodos de embebição de 12 e 24 horas, a escarificação na lateral revelou-se tão eficiente quanto à escarificação no lado oposto ao hilo e, ambas superiores às sementes intactas.

Os períodos de embebição não afetaram a primeira contagem para as sementes intactas. Já para as sementes escarificadas nas regiões lateral e oposta ao hilo observa-se aumento na primeira contagem nos tempos de embebição de 12 e 24 horas, sendo iguais entre si e ambos superiores a primeira contagem das sementes não embebidas.

$\mathrm{Na}$ escarificação mecânica, o maior percentual de emergência das plântulas de $C$. fistula foi obtido quando as sementes foram escarificadas na região lateral ao hilo, sendo significativamente superior a emergência das plântulas provenientes das sementes intactas e escarificadas na região oposta ao hilo (Tabela 2). Já o menor percentual de emergência de plântulas foi promovido pelas sementes intactas, sendo inferior aos tratamentos mecânicos. Em ralação aos períodos de embebição para a emergência das plântulas de $C$. fistula, não se observou diferenças significativas para os períodos avaliados.
A escarificação mecânica mostrou eficiência na superação da dormência em sementes de C. fistula, pois promoveu aumento na primeira contagem e na emergência de plântulas, o que pode ser atribuído à abertura de fissuras que promovem o rompimento do tegumento e facilitam o início da germinação. Quanto a primeira contagem, resultados semelhantes foram encontrados para Cassia fistula (LOPES et al., 2003), Caesalpinia pyramidalis Tul (ALVES et al., 2007), Zizyphus joazeiro Mart. (ALVES et al., 2008), Adenanthera pavonina L. (RIBEIRO; BRAZ; BRITO, 2009).

Neste trabalho, o maior percentual de emergência de plântulas de C. fistula foi obtido quando as sementes foram escarificadas na região lateral ao hilo $(95,67 \%)$. Esse resultado foi superior ao evidenciado por Lopes et al. (2003) para esta espécie, onde o maior percentual de germinação foi obtido quando as sementes foram escarificadas mecanicamente $(87,5 \%)$, sendo estatisticamente igual aos resultados obtidos quando as sementes foram escarificadas com ácido sulfúrico por 5 $(58,75 \%), 10(75 \%), 15(65 \%), 30(77,5 \%)$ e 60 $(68,75 \%)$ minutos. Com sementes de Ormosia arborea (Vell.) Harms, Basqueira et al. (2011) observaram que a escarificação com lixa na porção mediana da face lateral laranja-avermelhada proporcionou melhor superação de dormência. 
Tabela 2. Primeira contagem, emergência, índice de velocidade de emergência e tempo médio de emergência de plântulas de Cassia fistula L., após tratamentos pré-germinativos, Areia-PB, 2009.

\begin{tabular}{|c|c|c|c|c|}
\hline \multirow{3}{*}{ Escarificação } & \multicolumn{3}{|c|}{ Tempo de Embebição (horas) } & \multirow{3}{*}{ Média } \\
\hline & 0 & 12 & 24 & \\
\hline & \multicolumn{3}{|c|}{ Primeira Contagem (\%) } & \\
\hline Sem & $2,0 \mathrm{aB}$ & $0,0 \mathrm{aB}$ & $0,0 \mathrm{aB}$ & 0,7 \\
\hline $\mathrm{Na}$ Lateral & $18,0 \mathrm{bA}$ & $65,0 \mathrm{aA}$ & $59,0 \mathrm{aA}$ & 47,3 \\
\hline Oposto ao Hilo & $9,0 \mathrm{bAB}$ & $54,0 \mathrm{aA}$ & $40,0 \mathrm{aA}$ & 34,3 \\
\hline Média & 9,7 & 39,7 & 33,0 & \\
\hline \multicolumn{5}{|c|}{ Emergência (\%) } \\
\hline Sem & 2,0 & 3,0 & 1,0 & $2,0 \mathrm{C}$ \\
\hline $\mathrm{Na}$ Lateral & 96,0 & 97,0 & 94,0 & $95,7 \mathrm{~A}$ \\
\hline Oposto ao Hilo & 90,0 & 86,0 & 76,0 & $84,0 \mathrm{~B}$ \\
\hline Média & $62,7 \mathrm{a}$ & $62,0 \mathrm{a}$ & $57,0 \mathrm{a}$ & \\
\hline \multicolumn{5}{|c|}{ Índice de Velocidade de Emergência } \\
\hline Sem & 0,07 & 0,07 & 0,02 & $0,05 \mathrm{C}$ \\
\hline $\mathrm{Na}$ Lateral & 3,04 & 3,29 & 3,16 & $3,16 \mathrm{~A}$ \\
\hline Oposto ao Hilo & 2,77 & 2,86 & 2,43 & $2,69 \mathrm{~B}$ \\
\hline Média & $1,96 \mathrm{a}$ & $2,08 \mathrm{a}$ & $1,87 \mathrm{a}$ & \\
\hline \multicolumn{5}{|c|}{ Tempo Médio de Emergência (Dias) } \\
\hline Sem & 0,0 & 6,0 & 0,0 & $2,0 \mathrm{~B}$ \\
\hline $\mathrm{Na}$ Lateral & 17,8 & 18,3 & 17,4 & $17,8 \mathrm{~A}$ \\
\hline Oposto ao Hilo & 22,7 & 20,7 & 18,9 & $20,8 \mathrm{~A}$ \\
\hline Média & $13,5 \mathrm{a}$ & $15,0 \mathrm{a}$ & $12,1 \mathrm{a}$ & \\
\hline
\end{tabular}

Médias seguidas da mesma letra minúscula na linha e maiúscula na coluna não diferem entre si pelo teste de Tukey ( $\mathrm{p} \leq 0,05)$.

Fonte: Elaboração dos autores.

O maior índice de velocidade de emergência (IVE) das plântulas de C. fistula, foi promovido pelas sementes escarificadas na região lateral ao hilo (Tabela 2). O menor índice de velocidade de emergência foi obtido com as sementes intactas, sendo este significativamente inferior aos tratamentos mecânicos. Já em relação ao tempo de embebição, não se observou diferenças estatísticas para o índice de velocidade de emergência para os períodos avaliados.

Em relação ao tempo médio gasto para que ocorresse a emergência, observa-se que não houve diferenças estatísticas entre os tratamentos mecânicos, escarificação nas regiões lateral e oposta ao hilo (Tabela 2). Ainda sobre os tratamentos mecânicos, analisa-se que o menor tempo de emergência das plântulas foi das sementes intactas, sendo este tempo inferior ao dos tratamentos mecânicos. Deve-se ressaltar que, esse menor tempo de emergência se deve ao baixo percentual de emergência das sementes intactas e não ao fato que, este tratamento tenha propiciado melhor expressão do vigor das sementes. Já os períodos de embebição avaliados não afetaram o tempo médio de emergência.

De acordo com Lopes et al. (2003), a escarificação mecânica aumentou o índice de velocidade de germinação de sementes de Cassia fistula. A relevância da posição da escarificação da semente decorre, provavelmente, das variações que as aberturas podem promover na absorção de água, bem como na parte do embrião que for diretamente atingida, uma vez que o funcionamento das atividades fisiológicas de 
germinação é comprometido quando a absorção de água pelas sementes é deficiente (BEWLEY; BLACK, 1994).

Neste trabalho, observa-se que a fissura feita pela da escarificação promoveu os maiores percentuais de emergência e índices de velocidade de emergência, podendo-se evidenciar também para a espécie que quanto mais próximo à entrada de água do embrião maior as respostas em vigor das plântulas (Tabela 2). Sementes de C. fistula possuem hilo diminuto, arredondado e sua testa é lisa e rígida com poros na região hilar e endosperma de consistência dura (ARAÚJO; MATOS, 1991). Por isso, a escarificação em sementes de C. fistula foi tão eficiente na superação da dormência. Devese ressaltar também que a posição da escarificação está relacionada diretamente com a superação de dormência das sementes de Fabaceae, pois se tem observado que a maior proximidade da fissura no tegumento com o embrião tem favorecido a embebição e a germinação (COELHO et al., 2010; BASQUEIRA et al., 2011).

O desempenho das plântulas de C. fistula, relacionado ao crescimento, em função dos tratamentos pré-germinativos estão apresentados na Tabela 3. A escarificação na lateral e no lado oposto ao hilo proporcionaram maior comprimento da parte aérea das plântulas de C. fistula (Tabela 3), sendo estes iguais entre si e superiores ao comprimento da parte aérea das plântulas originárias das sementes intactas. Os períodos de embebição avaliados não afetaram o comprimento da parte aérea.
A escarificação nas regiões lateral e lado oposto ao hilo proporcionaram maior comprimento da raiz das plântulas de C. fistula (Tabela 3), sendo estes iguais entre si e superiores ao comprimento da raiz das plântulas provenientes das sementes intactas. Os períodos de embebição avaliados não afetaram significativamente o comprimento da raiz.

Em sementes de Caesalpinia pyramidalis Tul, Alves et al. (2007) também encontraram diferenças significativas para o comprimento da parte aérea e da raiz, em que as plântulas procedentes das sementes escarificadas com lixa foram superiores àquelas do controle. Entretanto, Alves et al. (2008) estudando sementes de Zizyphus joazeiro Mart. e Coelho et al. (2010) avaliando sementes de Caesalpinia ferrea Max ex Tul, encontraram que apenas o comprimento da parte aérea das plântulas provenientes das sementes escarificadas foram superiores às do controle. Para Andrade et al. (2010), a posição da escarificação, em sementes de Hymenaea courbaril L., é um fator determinante que afetou o comprimento da parte aérea e da raiz das plântulas.

O maior acúmulo de massa seca na parte aérea das plântulas de $C$. fistula, em função dos tratamentos mecânicos, foi proporcionado pelas sementes escarificadas na região lateral ao hilo, sendo estatisticamente igual ao acúmulo de massa seca do tratamento escarificação oposta ao hilo (Tabela 3). Já o menor acúmulo de massa seca foi proporcionado pelo tratamento sem escarificação, sendo este igual ao tratamento representado pela escarificação no lado oposto ao hilo. 
Tabela 3. Comprimento da parte aérea e da raiz e massa da matéria seca da parte aérea e da raiz de plântulas de Cassia fistula L., após tratamentos pré-germinativos, Areia-PB, 2009.

\begin{tabular}{|c|c|c|c|c|}
\hline \multirow{3}{*}{ Escarificação } & \multicolumn{3}{|c|}{ Tempo de Embebição (horas) } & \multirow{3}{*}{ Média } \\
\hline & 0 & 12 & 24 & \\
\hline & \multicolumn{3}{|c|}{ Comprimento da Parte Aérea $(\mathrm{cm})$} & \\
\hline Sem Escarificação & 2,63 & 5,25 & 1,50 & $3,13 \mathrm{~B}$ \\
\hline $\mathrm{Na}$ Lateral & 8,14 & 7,21 & 6,39 & $7,25 \mathrm{~A}$ \\
\hline Oposto ao Hilo & 7,80 & 7,96 & 6,60 & $7,45 \mathrm{~A}$ \\
\hline \multirow[t]{2}{*}{ Média } & $6,19 \mathrm{a}$ & $6,81 \mathrm{a}$ & $4,83 \mathrm{a}$ & \\
\hline & \multicolumn{3}{|c|}{ Comprimento da Raiz (cm) } & \\
\hline Sem Escarificação & 4,13 & 4,88 & 1,75 & $3,59 \mathrm{~B}$ \\
\hline $\mathrm{Na}$ Lateral & 9,72 & 8,77 & 7,51 & $8,67 \mathrm{~A}$ \\
\hline Oposto ao Hilo & 8,84 & 9,14 & 6,7 & $8,23 \mathrm{~A}$ \\
\hline \multirow[t]{2}{*}{ Média } & $7,56 \mathrm{a}$ & $7,6 \mathrm{a}$ & $5,32 \mathrm{a}$ & \\
\hline & \multicolumn{3}{|c|}{ Massa da Matéria Seca da Parte Aérea (g) } & \\
\hline Sem Escarificação & 0,04 & 0,11 & 0,02 & $0,06 \mathrm{~B}$ \\
\hline $\mathrm{Na}$ Lateral & 0,14 & 0,11 & 0,09 & $0,11 \mathrm{~A}$ \\
\hline Oposto ao Hilo & 0,10 & 0,12 & 0,08 & $0,10 \mathrm{AB}$ \\
\hline \multirow[t]{2}{*}{ Média } & $0,09 \mathrm{ab}$ & $0,12 \mathrm{a}$ & $0,06 \mathrm{~b}$ & \\
\hline & \multicolumn{3}{|c|}{ Massa da Matéria Seca da Raiz (g) } & \\
\hline Sem Escarificação & 0,02 & 0,02 & 0,03 & $0,02 \mathrm{~A}$ \\
\hline $\mathrm{Na}$ Lateral & 0,04 & 0,04 & 0,03 & $0,03 \mathrm{~A}$ \\
\hline Oposto ao Hilo & 0,03 & 0,03 & 0,02 & $0,03 \mathrm{~A}$ \\
\hline Média & $0,03 \mathrm{a}$ & $0,03 \mathrm{a}$ & $0,03 \mathrm{a}$ & \\
\hline
\end{tabular}

Médias seguidas da mesma letra minúscula na linha e maiúscula na coluna não diferem entre si pelo teste de Tukey ( $\mathrm{p} \leq 0,05)$.

Fonte: Elaboração dos autores.

Em relação ao tempo de embebição (Tabela 3), o período de 12 horas foi o que proporcionou o maior acúmulo de massa seca na parte aérea, não havendo diferenças significativas com o acúmulo de massa das plântulas oriundas das sementes não embebidas. Já o menor acúmulo de massa seca da parte aérea foi constatado no tempo de 24 horas de embebição, sendo estatisticamente igual ao tratamento sem embebição.

Em relação ao acúmulo de massa seca na raiz, os tratamentos mecânicos e os períodos de embebição não o afetaram significativamente (Tabela 3). Como evidenciado neste trabalho, o acúmulo de massa seca na parte aérea foi mais sensível na avaliação do vigor quando comparado com as respostas de acúmulo de massa seca na raiz de plântulas de $C$. fistula. Coelho et al. (2010), com sementes de $C$. ferrea também observaram que a escarificação com lixa proporcionou plântulas com maior acúmulo de massa seca na parte aérea, porém, na raiz a posição da escarificação foi um fator determinante para um maior acúmulo de massa seca. Em sementes de C. pyramidalis, a escarificação com lixa não proporcionou plântulas com maior acúmulo de massa seca na parte aérea e na raiz (ALVES et al., 2007) e, em sementes de $Z$. joazeiro, as sementes escarificadas com lixa proporcionaram plântulas com maior massa seca tanto na parte aérea como na raiz (ALVES et al., 2008).

\section{Conclusões}

Os frutos de Cassia fistula possuem, em média, 41,4 cm de comprimento, 18,9 mm de diâmetro, 
20,9 mm de espessura, 67,3 g de massa, 53 sementes normais e 3 sementes danificadas;

As sementes de $C$. fistula têm, em média, 8,28 $\mathrm{mm}$ de comprimento, $6,25 \mathrm{~mm}$ de diâmetro, 3,54 $\mathrm{mm}$ de espessura e 147,4 mg de massa;

As escarificações são eficientes para superação da dormência de sementes de $C$. fistula favorecendo os processos de emergência e crescimento inicial;

Os períodos de embebição não afetam a emergência e o crescimento inicial das plântulas de C. fistula.

\section{Referências}

ALVES, E. U.; BRAGA-JÚNIOR, J. M.; BRUNO, R. de L. A.; OLIVEIRA, A. P. de; CARDOSO, E. de A; ALVES, A. U.; ALVES, A. U.; SILVA, K. B. Métodos para quebra de dormência em unidades de dispersão de Zizyphus joazeiro Mart. (RHAMNACEAE). Revista Árvore, Viçosa, MG, v. 32, n. 3, p. 407-415, 2008.

ALVES, E. U.; CARDOSO, E. de A.; BRUNO, R. de L. A.; ALVES, A. U.; ALVES, A. U.; GALINDO, E. A.; BRAGA-JÚNIOR, J. M. Superação de dormência em sementes de Caesalpinia pyramidalis Tul. Revista Árvore, Viçosa, MG, v. 31, n. 3, p. 405-415, 2007.

ANDRADE, L. A.; BRUNO, R. de A.; OLIVEIRA, L. S. B. de; SILVA, H. T. F. da. Aspectos biométricos de frutos e sementes, grau de umidade e superação de dormência de jatobá. Acta Scientiarum Agronomy, Maringá, v. 32, n 2, p. 293-299, 2010.

ARAÚJO, S. S.; MATOS, V. P. Morfologia da sementes e de plântulas de Cassia fistula L. Revista Árvore, Viçosa, MG, v. 15, n. 3, p. 217-223, 1991.

AYRES, M.; AYRES-JÚNIOR, M.; AYRES, D. L.; SANTOS, A. A. S. BioEstat: aplicações estatísticas nas áreas de ciências biométricas. Versão 5.0. Belém: Sociedade Civil Mamirauá, MCT/CNPq, 2007. 364 p.

BASQUEIRA, R. A.; PESSA, H.; SOUZA-LEAL, T. de; PEDROSA-DE-MORAES, C. Superação de dormência em Ormosia arborea (Fabaceae: Papilionoideae) pela utilização de dois métodos de escarificação mecânica em diferentes pontos do tegumento. Revista em Agronegócios e Meio Ambiente, Maringá, v. 4, n. 3, p. 547-561, 2011.

BEWLEY, J. D.; BLACK, M. Seeds: physiology of development and germination. 2. ed. New York: Plenum Press, 1994. 445 p.
BRANCALION, P. H. S.; MARCOS FILHO, J. Distribuição da germinação no tempo: causas e importância para a sobrevivência das plantas em ambientes naturais. Informativo ABRATES, Londrina, v. 18, n. 1,2,3, p. 11-17, 2008.

BRASIL. Regras para análise de sementes. Brasília: MAPA/ACS, 2009. 399 p.

COELHO, M. de F. B.; MAIA, S. S. S.; OLIVEIRA, A. K. de; DIÓGENES, F. E. P. Superação da dormência tegumentar em sementes de Caesalpinia ferrea Mart ex Tul. Revista Brasileira de Ciência Agrária, Recife, v. 5, n. 1, p. 74-79, 2010.

CORRÊA, M. P. Dicionário de plantas úteis do Brasil e exóticas cultivadas. Rio de Janeiro: MA/IBDF, 1984. v. $1,747 \mathrm{p}$.

DUTRA, A. S.; MEDEIROS FILHO, S.; TEÓFILO, E. M.; DINIZ, F. O. Germinação de sementes de Senna siamea (Lam.) H.S. Irwin E Barneby - Caesalpinoideae. Revista Brasileira de Sementes, Brasília, v. 29, n. 1, p. 160-164, 2007.

FENNER, M. Seed ecology. London: Chapman e Hall, 1993. $151 \mathrm{p}$.

FERREIRA, D. F. Sisvar versão 5.3. [s.l.] : DEX/UFLA, 2010. $66 \mathrm{p}$.

FOWLER, J. A. P.; BIANCHETTI, A. Dormência em sementes florestais. Colombo: EMBRAPA-Florestas, 2000. $28 \mathrm{p}$.

GALINDO, C. A. M. Absorção de água, germinação $e$ dormência de sementes de mucuna preta. 2006. Dissertação (Mestrado em Agronomia) - Universidade Estadual Paulista. Faculdade de Ciências Agrárias e Veterinárias, Campus de Jaboticabal, Jaboticabal.

LEISHAMAN, M. R.; WRIGHT, I. J.; MOLES, A. T.; WESTOBY, M. The evolutionary ecology of seed size. In: FENNER, M. (Ed.). Seeds: the ecology of regeneration in plant communities. Wallingford: CAB International, 2000. p. 31-57.

LOPES, J. C.; SILVA, G. F. da; POSSE, S. C. P.; RUY, J. Germinação e dormência de sementes de Cassia fistula L. Brasil Florestal, Brasília, n. 78, p. 67-74, 2003.

MAGUIRE, J. D. Speed of germination aid in selection and evaluation for seedling emergence and vigor. Crop Science, Madison, v. 2, n. 2, p. 176-77, 1962.

MARCOS FILHO, J. Fisiologia de sementes de plantas cultivadas. Piracicaba: FEALQ, 2005. 495 p.

NAKAGAWA, J.; CAVARIANI, C.; ZUCARELI, C.; MARTINS, C. C. Viabilidade de sementes de mucunapreta em função do tamanho, da maturação e da secagem. 
Acta Scientiarum Agronomy, Maringá, v. 29, n. 1, p. 107112, 2007.

NOODÉN, L. D.; BLAKEY, K. A.; GRZYBOWSKI, J. $\mathrm{M}$. Control of seed coat thickness and permeability in soybean: a possible adaptation to stress. Plant Physiology, Waterbury, v. 79, n. 2, p. 543-545, 1985.

OLIVEIRA, A. B. de; MEDEIROS-FILHO, S.; BEZERRA, A. M. E.; BRUNO, R. de L. A. Emergência de plântulas de Copernicia hospita Martius em função do tamanho da sementes, do substrato e do ambiente. Revista Brasileira de Sementes, Brasília, v. 31, n. 1, p. 281-287, 2009.

ORWA, C.; MUTUA, A.; KINDT, R.; JAMNADASS, R.; SIMONS, A. Agroforestree database: a tree reference and selection guide version 4.0. Giriri: Word Agroforestry Center, 2009. Disponível em: $<$ http://www. worldagroforestry.org/af/treedb/>. Acesso em: 25 jun. 2011.

RIBEIRO, V. V.; BRAZ, M. do S. S.; BRITO, N. M. de. Tratamentos para superar a dormência de sementes de tento. Revista Biotemas, Florianópolis, v. 22, n. 4, p. 2532, 2009.

ROCAS, A. N. Cassia fistula L. In: VOZZO, J. A. Tropical tree seed manual. Washington: United States Department of Agriculture, Forest Service, 2002. p. 366368.
RODRIGUES, A. C. C.; OSUMA, J. T. A.; QUEIROZ, S. R. O. D.; RIOS, A. P. S. Biometria de frutos e sementes e grau de umidade de sementes de angico (Anadenanthera colubrina (Vell.) Brenan var. cebil (Griseb.) Altschul) procedentes de duas áreas distintas. Revista Científica Eletrônica de Engenharia Florestal, Garça, v. 4, n. 8, p. 1-15, 2006.

RODRIGUES, A. P. D. C.; KOHL, M. C.; PEDRINHO, D. R.; ARIAS, E. R. A.; FAVERO, S. Tratamentos para superar a dormência de sementes de Acacia mangium Willd. Acta Scientiarum Agronomy, Maringá, v. 30, n. 2, p. 279-283, 2008.

SANTOS, M. R. A.; PAIVA, R.; GOMES, G. A. C.; PAIVA, P. D. O.; PAIVA, L. V. Estudos sobre superação de dormência em sementes de Smilax japecanga Grisebach. Ciência Agrotécnica, Lavras, v. 27, n. 2, p. 319-324, 2003.

SILVA NETO, M. A. da; MACEDO, M. L. A. de; ANDRADE, A. R. S. de; FREITAS, J. C. de; PEREIRA, E. R. R. Análise do perfil agrícola do perímetro irrigado de São Gonçalo-PB. Pesquisa Aplicada \& Agrotecnologia, Guarapuava, v. 5, n. 2, p. 155-163, 2012.

VAUGHTON, G.; RAMSEY, M. Sources and consequences of seed mass variation in Banksia marginata (Proteaceae). Journal of Ecology, London, v. 86, n. 4, p. 563-573, 1998. 
